\title{
Changes in the Cortical Map of the Hand following Postnatal Median Nerve Injury in Monkeys: Modification of Somatotopic Aggregates
}

\author{
John T. Wall, ${ }^{1}$ Michael F. Huerta, ${ }^{2}$ and Jon H. Kaas ${ }^{3}$ \\ 'Department of Anatomy, Medical College of Ohio, Toledo, Ohio 43699, ²Department of Biostructure and Function, \\ University of Connecticut Health Center, Farmington, Connecticut 06032, and ${ }^{3}$ Department of Psychology, Vanderbilt \\ University, Nashville, Tennessee 37240
}

\begin{abstract}
Median nerves to the hands of 8-15-d-old marmoset monkeys were transected and precluded from regeneration by ligation. Following periods of 0.4-1.5 years, features of organization in the cortical area $3 \mathrm{~b}$ hand map were assessed neurophysiologically, and compared to features in normally reared monkeys.

Cortical features in monkeys with both histories were similar in certain respects. (1) Receptive field organization was similar in terms of tactile thresholds and receptive field size, continuity, and glabrous-hairy specificity. (2) Somatotopic organization was similar in terms of the continuity of the glabrous representation, and progressions of receptive field shifts across some parts of the hand map. (3) Finally, the overall size of the hand map did not change.
\end{abstract}

In contrast, other cortical features clearly differed following these developmental histories. (1) Neurons at virtually all recording sites in normal hand maps responded to light mechanical stimulation, whereas, following injury, neurons at about $8 \%$ of the recording sites responded only to highintensity stimuli. (2) Somatotopic organization differed in terms of the presence or absence of the representation of skin autonomously innervated by the median nerve, the number and continuity of representations of hairy skin, and the spatial interfacing of representations. (3) Finally, there were differences in the areas and widths of representations of parts of the hand. The overall impression is that there is a correspondence between the cortical features that changed most after injury, and the features that varied most in individual normal monkeys: in both circumstances the most variable features involved properties of spatial patterning across large aggregates of neurons as reflected by the size, shape, continuity, and interfacing of representations.

A hypothesis is proposed that suggests that the cortical hand map normally consists of a number of representations that are capable of developing and surviving somewhat autonomously of each other. The features of spatial patterning in the mosaiclike map of these representations are influenced by postnatal availability of inputs from intact hand nerves.

\footnotetext{
Received May 23, 1991; revised Mar. 26, 1992; accepted Mar. 31, 1992

This work was supported by National Institutes of Health Grants NS 21105 and NS 16446. We thank Kelly Bergen and Vincent Nepomuceno for their patient and skillful assistance. We are also very grateful to Bob Rhoades for comments on the manuscript.

Correspondence should be addressed to Dr. J. T. Wall at the above address. Copyright (C) 1992 Society for Neuroscience $0270-6474 / 92 / 123445-11 \$ 05.00 / 0$
}

The development of the somatosensory system in human and nonhuman primates hegins prenatally and extends into the postnatal period (e.g., Goldman-Rakic and Brown, 1982; Meisami and Timiras, 1982; Rakic et al., 1986; Reisman, 1987; Huntley et al., 1988; Peters and Jones, 1988; Darian-Smith et al., 1990). Peripheral nerve damage in infants and children causes a range of changes in touch perception that may or may not remain apparent in later life (e.g., Weinstein, 1969; Frykman, 1976; Mailander et al., 1989). Given the normal time course of development, it seems likely that this range of perceptual outcomes reflects a corresponding range of brain changes that result from alterations in postnatal development. How is postnatal development altered, and what are these changes?

To address this question, the present experiments assessed how postnatal nerve injury affects processing of touch information in the primatc cortex. The specific goal was to determine how features of organization in the primary somatosensory cortical hand map are changed when monkeys were raised under normal conditions, with a usual complement of three nerves from the hand, versus when monkeys underwent postnatal median nerve injury and rearing with two hand nerves. These experiments were pursued in a second study in which organization in these groups was compared to the organization in monkeys that, due to early injury of two hand nerves, were raised with only one hand nerve (see companion article, Wall et al., 1992).

\section{Materials and Methods}

Experimental sample. Experiments were conducted on eight marmoset monkeys (Callithrix jacchus). Five monkeys developed with normal innervation of the hand. The area $3 \mathrm{~b}$ hand cortex was sampled completely in three of these monkeys, whereas, in the remaining two animals, mapping was delimited to parts of the hand map. Three monkeys developed with hands innervated by normal ulnar and radial nerves, but with a sectioned and ligated median nerve. The area $3 b$ hand cortex was completely mapped in each of these monkeys.

Nerve transection and ligation. Eight- to fifteen-day-old infant monkeys were anesthetized with halothane and nitrous oxide. Using aseptic procedures, the median nerve was isolated, ligated near the wrist, and transected proximal to the ligature. The epineural sheath of the proximal stump was subsequently slid up the nerve, and the nerve was transected again at this level. The empty sheath was folded and ligated to form a closed ending. Postmortem dissections indicated the transected nerves ended in neuromas. Although it is difficult to rule out fiber regeneration completely, when examined under the dissecting microscope no processes were seen to extend from neuromas or into the wrist.

Neurophysiological mapping. Recordings were made from normal animals that were adolescent or adult in size. For the animals with transected nerves, one monkey was studied at 0.4 years of age, whereas the remaining monkeys ranged from 1.3 to 1.5 years. By size and breed- 


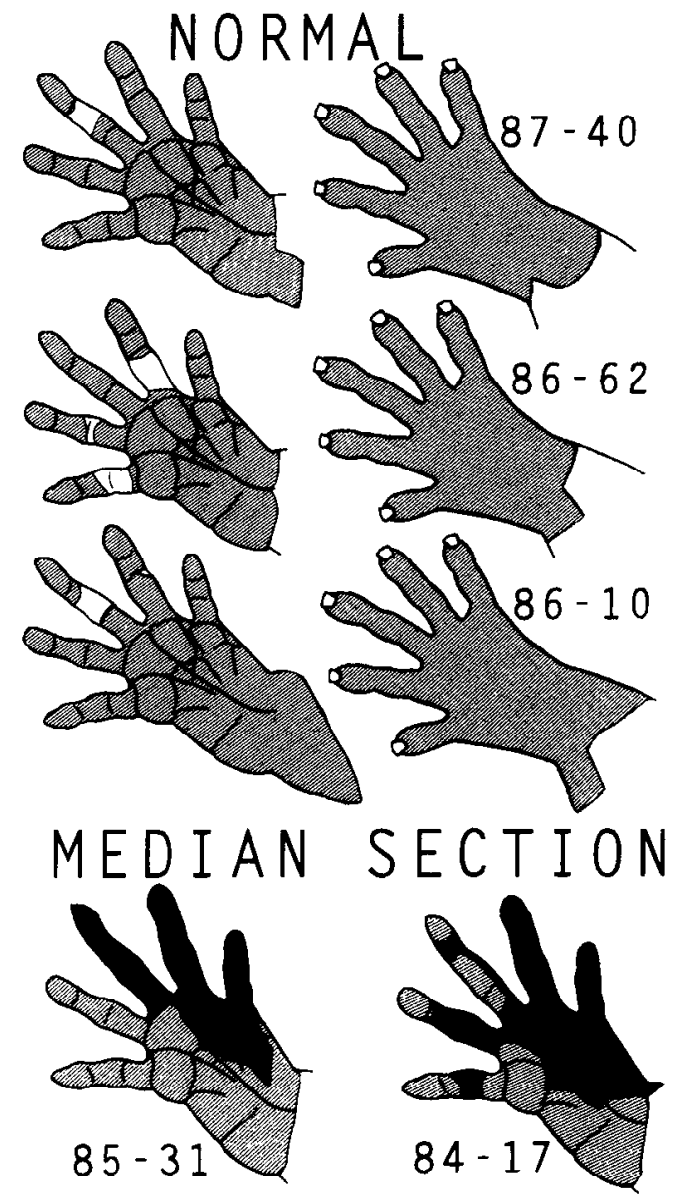

Figure 1. Shading indicates the summed receptive field areas of all recording sites in the cortical area $3 \mathrm{~b}$ hand maps of three normal monkeys $(t o p)$ and two monkeys reared after median nerve section (bottom). Except for small, inconsistently located zones (not shaded), the complete surface of the hand is represented in the cortical map of each normal monkey. In contrast, following median nerve section, the radial glabrous hand (black) was consistently denervated and not represented in the hand map. The denervated zone indicates the autonomous median nerve innervation territory. See Figure 4 for names of hand parts.

ing age for Callithrix, the older monkeys were adolescent or young adults.

Recording procedures were similar to those described previously (e.g., Wall et al., 1986). Monkeys were tranquilized and anesthetized (acepromazine, $0.4-0.8 \mathrm{mg} / \mathrm{kg}$, i.m., and ketamine hydrochloride, $25-50$ $\mathrm{mg} / \mathrm{kg}$, i.m.), and the head was positioned in a stereotaxic frame. Following exposure and photographing of the anterior parietal cortex, an array of penetrations was made across the area $3 \mathrm{~b}$ hand region and adjacent cortical regions. Penetrations were made with tungsten microelectrodes $(1-4 \mathrm{M} \Omega$, measured at $1 \mathrm{kHz})$ oriented perpendicular to the cortical surface. With some variance due to vasculature, efforts were made to space recording sites about $200 \mu \mathrm{m}$ apart. At each penetration, attempts were made to define a low-threshold field from multiple-unit discharges. Receptive fields were determined 400-900 $\mu \mathrm{m}$ below the surface, which localized the electrode tip around layer IV; however, similar fields were seen above and below these depths.

The stimuli consisted of hand-delivered contacts and brushes of the skin, hairs, and deep tissues. Cutaneous stimuli were presented so as to monitor the activity of receptors directly beneath the probe, rather than receptors affected by gross stimulus conduction across the skin. The defined receptive fields were judged to reflect the maximal field area of the recorded units. For a subsample of recording sites, Semmes-Weinstein filaments were used to estimate pressure thresholds from the centers of glabrous fields. Threshold values are expressed in terms of the markings on the filaments $[=\log 10($ force $\mathrm{mg})]$. To ensure objectivity in mapping, the investigator defining receptive fields did not know the location of the microelectrode during the experiment.

Upon completion of mapping, microlesions $(10 \mu \mathrm{A}, 10 \mathrm{sec})$ were made at selected recording sites, and the monkcys werc ovcrdosed with barbiturate and perfused. The brain was sectioned frozen, and cresyl violetstained sections were prepared to determine the locations of the microlesions and architectonic borders of area $3 b$.

Data analysis. Map data were evaluated using previously described procedures (Wall et al., 1986). The rostral and caudal borders of area $3 \mathrm{~b}$ were determined from cortical cytoarchitecture. The mediolateral extent of the hand map was determined from the borders with the representation of the wrist medially, and the face laterally. The borders and areas of representations of hand parts were delimited and measured with a planimeter using previously described procedures (Wall et al., 1986).

\section{Results}

\section{Hand surfaces represented in the cortical map}

Hand innervation was evaluated by summing receptive fields in experiments in which the hand cortex was completely mapped. With the exception of small, inconsistent regions on digits, virtually all hand regions were represented in each normal map (e.g., Fig. 1). In contrast, following section of the median nerve there was a consistent loss of glabrous inputs from $\mathrm{P} 2$, radial P1-TH, D1-D2, and part of all of D3 (e.g., Fig. 1). These findings indicate that median nerve section resulted in a chronic loss of low-threshold inputs from the pads and digits on the radial glabrous hand.

\section{Cortical activation at single recording sites}

\section{Responsiveness}

Neurons at virtually all recording sites in normal hand maps were highly responsive to light cutaneous stimulation. Responses from different glabrous subregions had similar pressure thresholds (e.g., Fig. 2). Following section of the median nerve, cortical neurons at most (mean - 92\%) recording sites wcre highly responsive to cutaneous stimulation. Neurons at the remaining $8 \%$ of sites responded to harder tap stimuli, but it was unclear whether activation was from high-threshold cutaneous and/or deep inputs. Since inputs were lost from the radial glabrous skin, light pressure thresholds were only measurable from the ulnar glabrous hand (Fig. 2). As in normal monkeys, there were no threshold differences for subdivisions of this skin; moreover, the thresholds for the overall ulnar side of the hand were normal (e.g., Fig. 2).

\section{Receptive field organization}

Size. Receptive field sizes in normal monkeys varied within a predictable range. Larger glabrous fields tended to be located proximally, spanning one to three palmar pads, and smaller fields tended to be located distally, on a single digit or digit phalanx (e.g., Fig. 3). Normal hairy fields varied from larger fields extending across much of the proximal hand, to smaller, more distally located fields extending across a single digit or nail bed. Following median nerve section, a normal gradient in relative field size was seen for proximodistal hand locations, and the absolute size of fields on a given hand location was similar to normal (e.g., Fig. 3).

Continuity. In both groups of monkeys, receptive ficlds typically extended across a continuous skin zone. Exceptions were recording sites with "split" fields on neighboring digits (e.g., Fig. 3 ). As reflected by similar small percentages of sites with split glabrous digit fields (e.g., normal $=4.7 \%$; median section $=$ $2.2 \%$ ), rearing with two versus three nerves did not result in major changes in the continuity of receptive fields. 

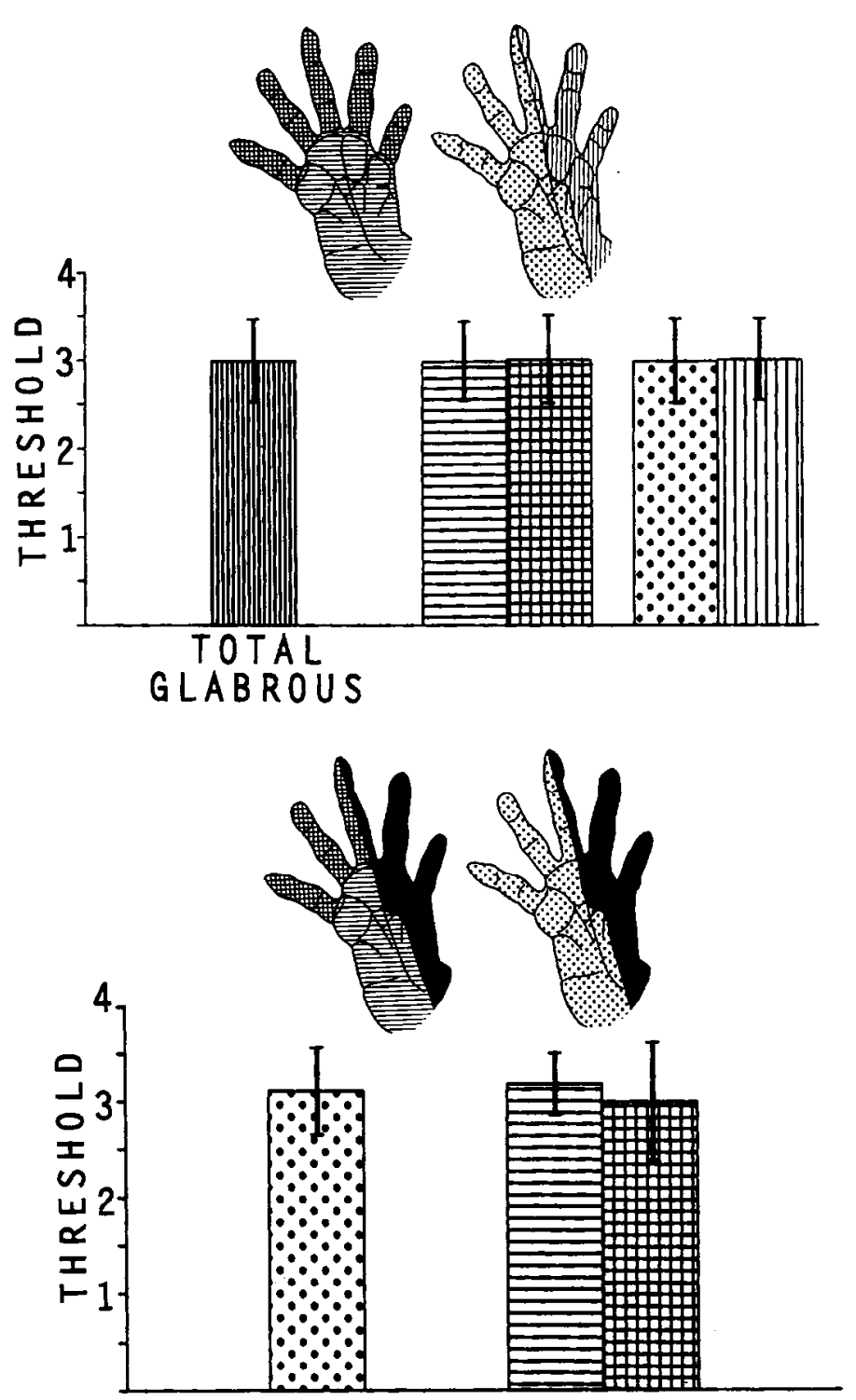

Figure 2. Tactile thresholds of cortical neuron responses to glabrous inputs in normal monkeys (top) and monkeys reared after median nerve section (bottom). Mean thresholds $( \pm \mathrm{SD})$ for different subregions of glabrous skin are indicatcd by the corresponding patterns of stippling and hatching on the hands and histogram bars. In normal monkeys, there were no differences in thresholds for the indicated radial versus ulnar side of the hand $(t[111]=0.22, p=0.82)$, or palm versus digit skin $(t[111]=0.25, p=0.80)$. In monkeys reared after median nerve section, denervation of the radial glabrous skin (black) resulted in no significant differences in thresholds for the indicated palm versus digit skin regions that remained innervated $(t[23]=1.01, p=0.32)$. In addition, thresholds on the innervated ulnar skin of median section monkeys did not differ from the normal thresholds for this skin $(t[91]=$ $1.10, p=0.27$ ).

Specificity. Receptive fields were normally specific to either glabrous or hairy skin; however, a mean of $2.8 \%$ of recording sites in normal monkeys had a "mixed" field involving both types of skin (e.g., Fig. 3). A similar percentage (3.1\%) of sites had a mixed field following median section.

\section{Cortical activation across multiple recording sites}

\section{Somatotopic organization}

The glabrous representation normally occupied a continuous block in the hand map (Fig. 4). Individual palmar pad repre-

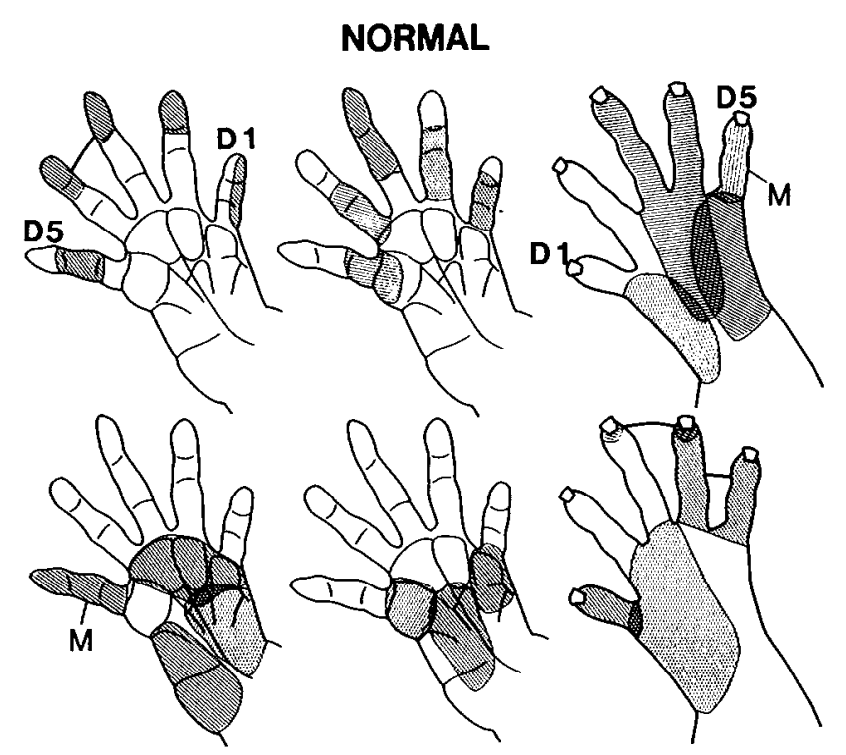

MEDIAN SECTION

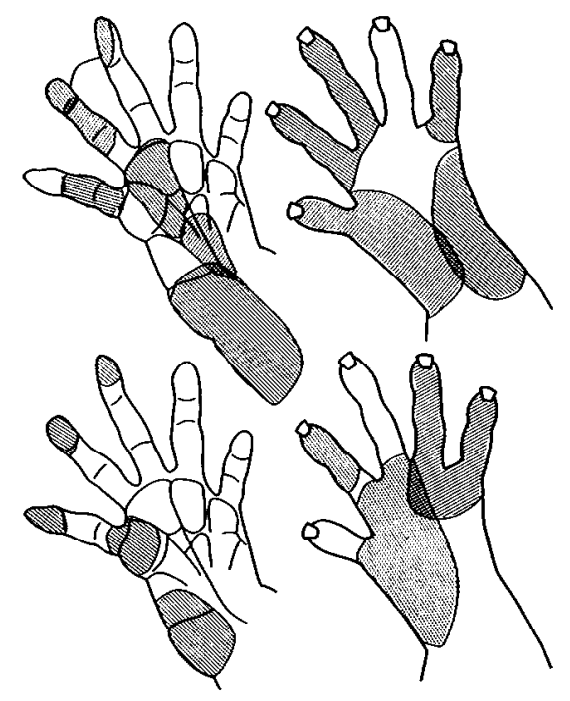

Figure 3. Examples of receptive fields in normal monkeys (top) and monkeys reared after median section (bottom). Each hatched area represents a receptive field defined from a multiple unit response at a single cortical recording site. "Split" fields observed at a single recording site are shown joined by lines. A "mixed" glabrous-hairy field is indicated by $M$. There were no major differences in receptive field size, or in the incidence of "split" and "mixed" fields, in normal monkeys and monkeys reared after median section.

sentations occupied caudal positions, with the representation of P1-TH laterally, PH medially, and P2 and P3-4-I in between (Figs. 4; 5, Row A). Digits D1 through D5 were represented rostrally in a similar lateromedial sequence (Figs. 4; 5, Row B). Caudorostral movements of recording sites generally led to receptive field shifts from proximal palm to more distal digits (Fig. 5, Rows C, D). The hairy representation normally occupied four to six discontinuous cortical regions, consistently located along the medial and lateral edges of the glabrous representation and, to a lesser extent, between the glabrous digit representations (Fig. 4). The medial patch or bandlike region represented the ulnar hairy hand and hairy D5, D4, and, to some degree, D3, whereas the lateral cortical bands or patches represented the radial hairy hand and hairy D1, D2, and, to some degree, D3 
Figure 4. Cortical area $3 \mathrm{~b}$ maps of the hand indicating the somatotopic organization of the representations of glabrous (white) and hairy (hatched) surfaces of the hand. $A$, Abbreviations for skin surfaces: $D 1-D 5$, digits $1-5 ; P I-$ $T H, P 1$ and thenar palmar pads; $P 2-$ $P 4, \mathrm{P} 2-\mathrm{P} 4$ palmar pads; $P I$, insular palmar pads; $P H$, hypothenar palmar pad; $H$, hairy hand between the wrist and knuckles; $F Q$, forequarter skin on the adjacent forelimb and trunk (not shown). $B-D$, Organization in normal monkeys. Note that there is a high degree of consistency in the arrangement of representations across individual monkeys, while at the same time, there is some variability in terms of the size, shape, continuity, and spatial interfacing of representations. $E$ and $F$, Organization in monkeys reared after median nerve injury. Note, first, that there is a high degree of interanimal consistency in the arrangement of representations while at the same time there is some variability in details of organization, and second, that the overall somatotopic pattern seen after median nerve section is clearly outside the range of variability seen in normal monkeys. Black regions indicate cortical areas where neurons were only responsive to higher-threshold inputs. The FQ representation was not included in the hand map but is consistently adjacent to the map. Scale bar, $1 \mathrm{~mm}$.
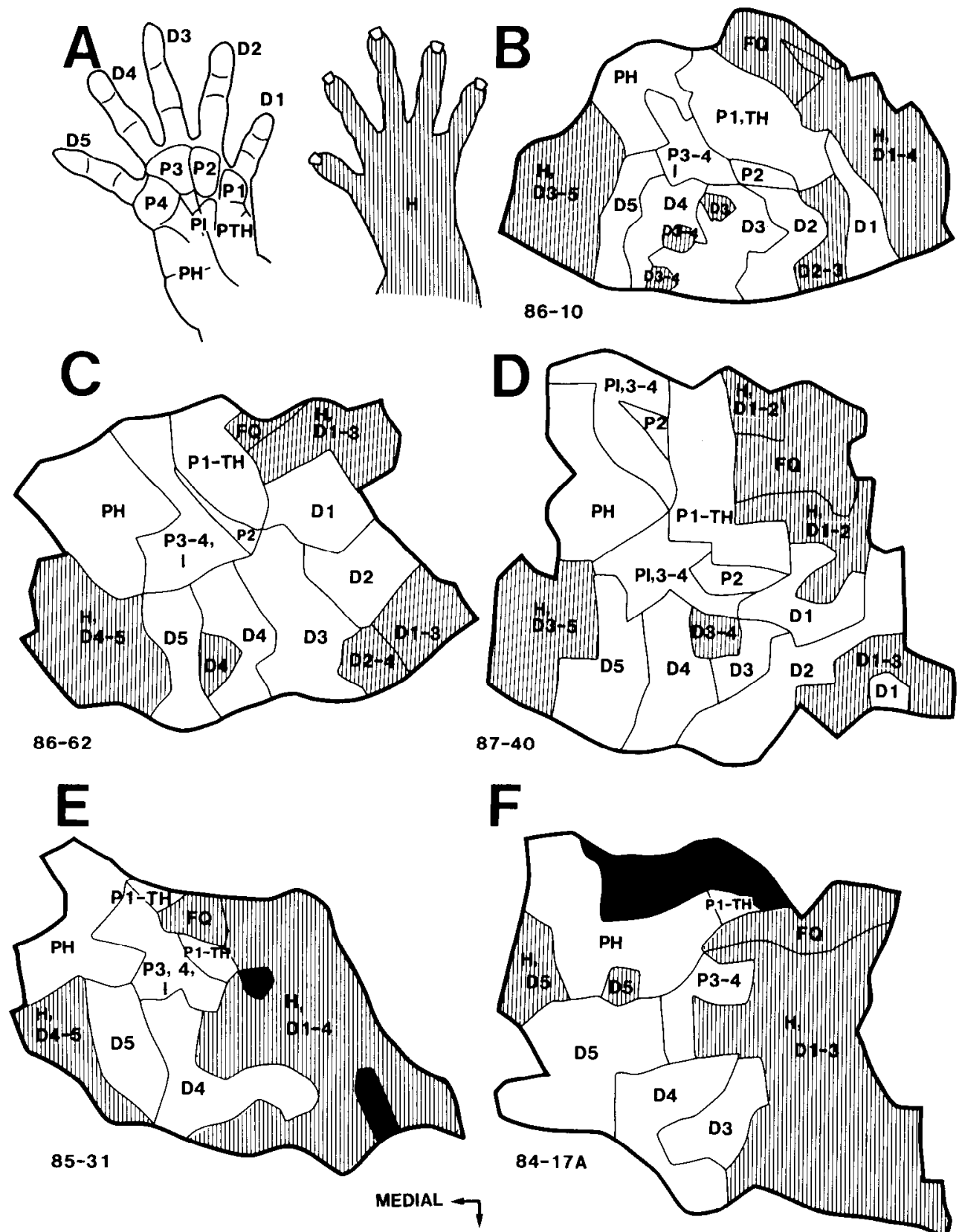

ANTERIOR

and D4 (Fig. 6). Cortical patches between glabrous digital representations represented hairy D4, D3, and, less consistently, D2.

In monkeys reared with two nerves, the representations of hand parts with intact innervation developed independent of the loss of neighboring representations, but were clearly shaped by the nerve injury. Similar to normal, the representation of the glabrous skin usually occupicd a continuous block (Fig. 4). Individual palmar pad representations occupied caudal locations, with the representation of PH medially, and P3-4-I more lateral (Figs. 4; 7, Row, A). Although a small representation of the proximal P1-TH pad was sometimes situated more laterally, there were no representations of radial $\mathrm{P} 1-\mathrm{TH}$ or $\mathrm{P} 2$. The representations of the glabrous digits were located rostral to the pad representations with D5 represented most medially and D4 more laterally (Figs. 4; 7, Row B). Although a representation of the ulnar glabrous D3 was sometimes seen, there were no glabrous representations of the radial D3, or D2 and D1. Glabrous digit and palm representations were in register with each other, and as a result, movements of recording sites in the caudorostral dimension led to relatively normal proximodistal shifts (e.g., Fig. 7, Row C). However, since the representation of the radial glabrous hand was absent, this organization only involved ulnar glabrous skin. In further contrast to normal organization, the hairy hand was represented in fewer than normal, that is, two to three discontinuous regions (Fig. 4). There was a high degree of specificity in these hairy representations, with the medial band(s) representing the ulnar hairy hand and hairy D5 and D4, and the lateral band representing the radial hairy hand and hairy D1-4 (Fig. 6). Unlike normal, the lateral band occupied space normally representing the radial glabrous hand, and as a result, the representations of the central parts of the glabrous hand and 


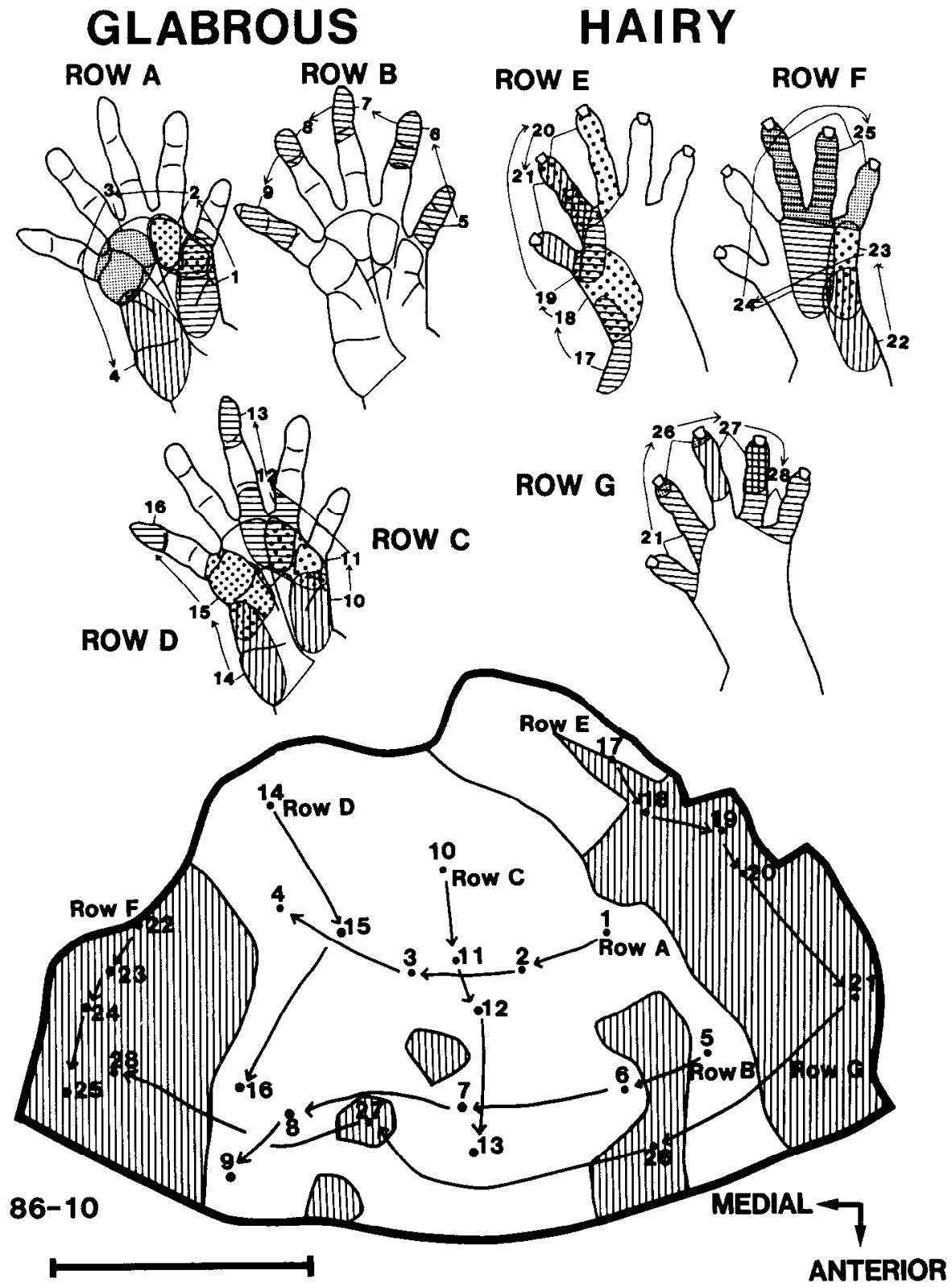

Figure 5. Shifts in receptive field location with lateromedial and caudorostral movements of cortical recording sites in a normally reared monkey. Note that the caudorostral axis of the hand map corresponds to the proximodistal axis of the hand, whereas the lateromedial cortical axis corresponds to the orthogonal axis across the hand. The representations of hairy (hatched) and glabrous (white) skin are organized in coarse register. Scale bar, $1 \mathrm{~mm}$. the D1 side of the hairy hand were continuous in lesion monkeys, whereas in normal monkeys the analogous mediolateral continuity was between representations of the central glabrous hand and the D1 side of the glabrous hand (Figs. 4, 5, 7). Thus, median section produced a novel somatotopic interfacing of glabrous and hairy representations.

\section{Size measurements}

Total hand map. The mean areas of the hand maps in normal and median-sectioned monkeys were not different (normal $=$ $3.64 \mathrm{~mm}^{2}$; median section $=3.75 \mathrm{~mm}^{2} ; t[4]=0.17, p=0.87$ ).

Hairy representations. In normal monkeys, a smaller percentage of the hand map represented the hairy hand $(33 \%)$ than the glabrous hand $(67 \%)(t[4]=6.38, p=0.003)$ whereas, following nerve section, the respective representations occupied comparable percentages of 44 and $47 \%$ of the map (Fig. 8 ). Thus, the overall hairy representation increased by about $11 \%$ due to median section. Looking at this change more closely, following median section the lateral cortical band representing the radial hairy hand and digits occupied $37 \%$ of the map, whereas the more medial band(s) representing the ulnar hand and digits occupied a smaller mean area of $7 \%$ (Fig. $8 ; t[4]=5.53$, $p=0.005$ ). In contrast, the analogous respective areas of $16 \%$ and $17 \%$ in normal monkeys were not different (Fig. 8). These data reflect two changes. First, the radial hairy representation increased above normal levels (Fig. $8 ; t[4]=3.96, p=0.01$ ). Consistent with this areal increase, there was an approximate doubling in the mean mediolateral width of this representation (normal $=368 \mu \mathrm{m}$; section $=744 \mu \mathrm{m}$ ). Second, following median injury there were decreases in the area and width of bands representing the ulnar hairy skin (Fig. 8; area decrease from 17\% to $7 \%, t[4]=2.63, p=0.05$; width decrease from 439 to 303 $\mu \mathrm{m}, t[4]=2.68, p=0.05)$. Thus, a $21 \%$ increase in the radial hairy representation and an offsetting $10 \%$ decrease in the ulnar hairy representation combined to produce a net increase in the overall hairy representation of $11 \%$ above normal. The offsetting 

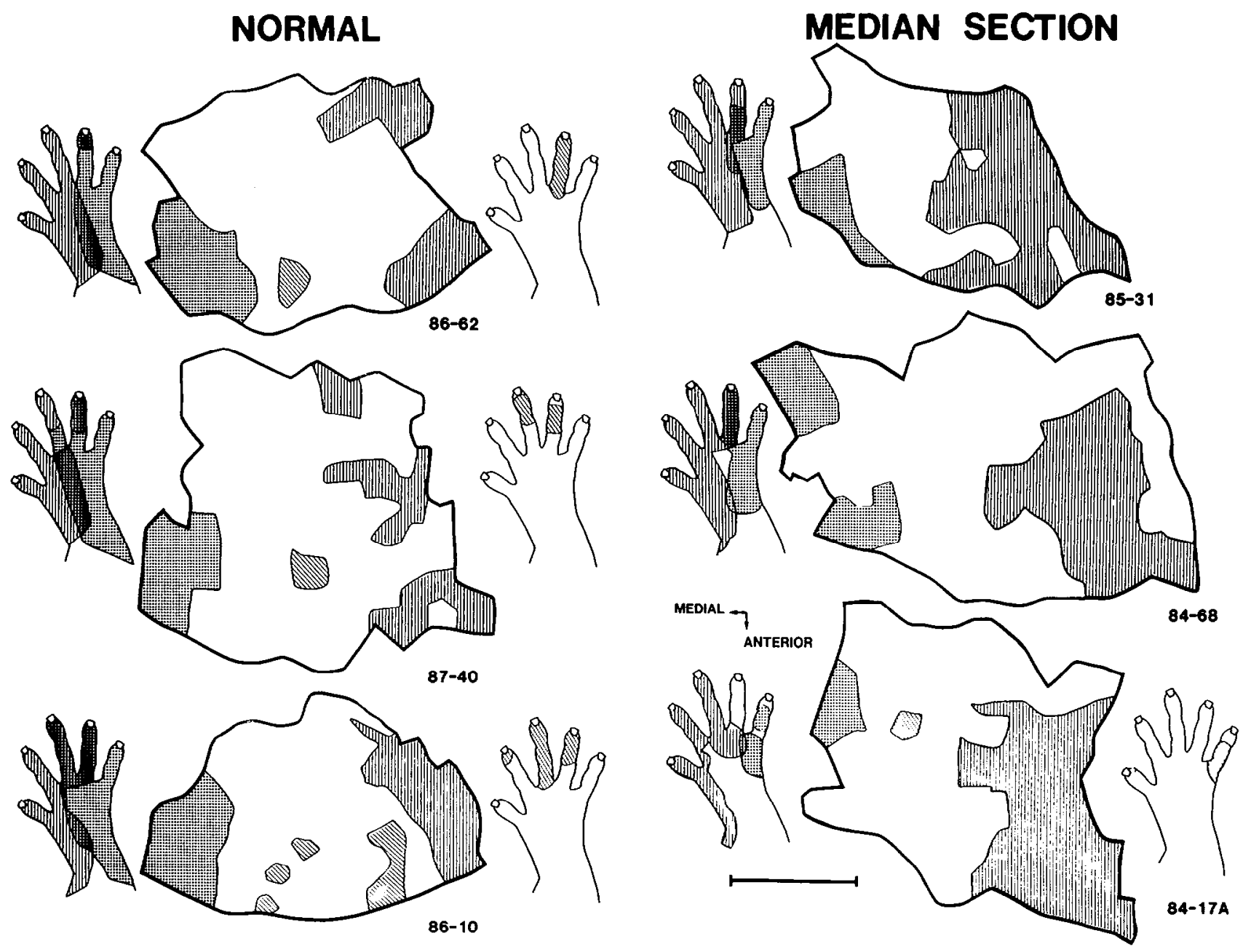

Figure 6. Specificity in the patterns of hairy hand representations in three normal monkeys $(l e f t)$ and three monkeys reared after median nerve section (right). As indicated by the stippling and hatching on the hands and maps, in normal monkeys, lateral hairy representations correspond to inputs from the radial hand, medial hairy representations correspond to inputs from the ulnar hand, and intervening patchlike representations correspond to inputs from middle digits. After median nerve section, the hairy hand is represented in fewer patches, the lateral representation of the radial skin increases in area, and the more medial representations of the middle digits and ulnar skin decrease in area. Scale bar, $1 \mathrm{~mm}$.

nature of these changes suggests some interaction in adjustments across the different hairy representations.

Glabrous representations. Insight into the size changes of glabrous representations requires attention to the glabrous innervation of the hand by the median and ulnar nerves. First, the glabrous skin that was not represented in cortex following median section provides an estimate of skin that is autonomously or exclusively innervated by the median nerve (Wall, 1990; J. $\mathrm{T}$. Wall, unpublished observations). By relating the receptive field defined at each cortical recording site to this denervated zone, it was possible to project this skin zone onto the maps of normal monkeys to estimate the cortical region that lost median inputs. This region involved a lateral band of cortex occupying a mean area of $30 \%$ of the map, with a mean mediolateral width of $499 \mu \mathrm{m}$ (Fig. 9, right column, hatching). Contrasting with loss of this representation, the sizes of other glabrous representations either increased or remained normal after rearing with two nerves. From previous nerve recording studies (Wall, 1990, unpublished observations), the glabrous skin that retained innervation after median section consists of two proximodistal strips. One strip, which includes the ulnar edge of PH, P4, and the entire glabrous D5, is normally autonomously innervated by the ulnar nerve, whereas the second strip, which includes the central palm and skin on glabrous D3 and D4, normally receives overlapping innervation from both the ulnar and median nerves. Employing the same approach described for defining the autonomous median representation, the autonomous ulnar and overlap strips were projected onto the cortical maps to estimate areas activated by these strips (Fig. 9). The band of cortex representing the autonomous ulnar glabrous skin occupied similar percentages of the maps of normal and median-injured monkeys (Fig. 9; normal $=15 \%$; median section $=16 \%$ ). Consistent with this areal constancy, the mean widths of this band were similar (i.e., normal $=299 \mu \mathrm{m}$; section $=336 \mu \mathrm{m}$ ). In contrast, the representation of the overlap skin occupied $22 \%$ of the normal hand map, and a significantly larger $31 \%$ of the map after median section (Fig. 9; $t[4]=3.21, p=0.03$ ). This areal increase involved a $34 \%$ increase in the mean width of this representation. This expanded representation of the middle palmar and glabrous digit skin partially offset the $30 \%$ decrease in glabrous representation that would be expected due to median nerve loss.

High-threshold representation. The final change involved some 
switching of cortical neuronal responsiveness from low-threshold to higher-threshold input at penetrations involving areas of about $9 \%$ of the hand map.

\section{Cortical variability}

There are two main findings regarding cortical variability. First, a few specific features of organization accounted for most individual variability in normal maps. These features involved representation: shapes (Fig. 4; e.g., compare D2), sizes (e.g., coefficient of variation for individual digit and pad representations was about 37\%), somatotopic interfacings (e.g., Fig. 4, compare relative adjacency of $\mathrm{PH}$ and $\mathrm{Pl}-\mathrm{TH}$ for 86-62 and 86-10), and spatial continuity (e.g., Fig. 4; compare location and number of hairy patches). These features are reflections of spatial patterning across large aggregates of cortical neurons. Second, these features that varied most in normally reared monkeys also changed the most following early nerve injury (see above results). However, it is clear that the cortical changes observed in monkeys reared with two nerves are beyond the range of individual variability seen in normal monkeys (Figs. 4, 6, 9).

\section{Discussion}

The present experiments are the first studies of the cortical consequences of neonatal nerve injury in primates. The results indicate how cortical organization is changed after early median nerve injury, and provide insight into somatotopic pattern formation in the hand map. Three main conclusions and a working hypothesis for summarizing the results are discussed.

\section{Conclusion 1. The differences in rearing conditions in the present study resulted in clear changes in spatial patterning, but only modest changes in neuronal response properties}

Most response properties surveyed at individual recording sites were similar in both groups of monkeys including, for example, response thresholds to glabrous inputs, receptive field size and continuity, and specificity of receptive fields to glabrous or hairy skin. The one local change detected with the employed methods was that, following injury, neurons at $8 \%$ of cortical sites were responsive only to higher-intensity mechanical stimulation. The overall impression from these results is that postnatal development with innervation from two, rather than the normal three, nerves resulted in relatively modest alterations in features of organization reflected at single cortical sites.

In contrast, there were clear differences in the features of spatial patterning reflected in the responses of aggregates of neurons recorded across multiple recording sites. Included in these alterations were (1) increases and decreases in the sizes of glabrous and hairy representations, (2) changes in the spatial continuity and distribution of hairy representations, and (3) changes in the somatotopic interfacing of representations.

The present findings are consistent with reports from nonprimate mammals that demonstrate that cortical neuron response properties can be relatively normal following early peripheral injury (e.g., Kalaska and Pomeranz, 1979; Simons et al., 1984; Wall and Cusick, 1986), bul contrast somewhat with other evidence that abnormal response properties can also be developed (e.g., Killackey et al., 1978; Kelahan et al., 1981). At present, the factors that lead to normal versus abnormal response properties remain undefined but probably include the nature of the injury (see Wall et al., 1992). Previous studies in nonprimate mammals have also demonstrated cortical somato-
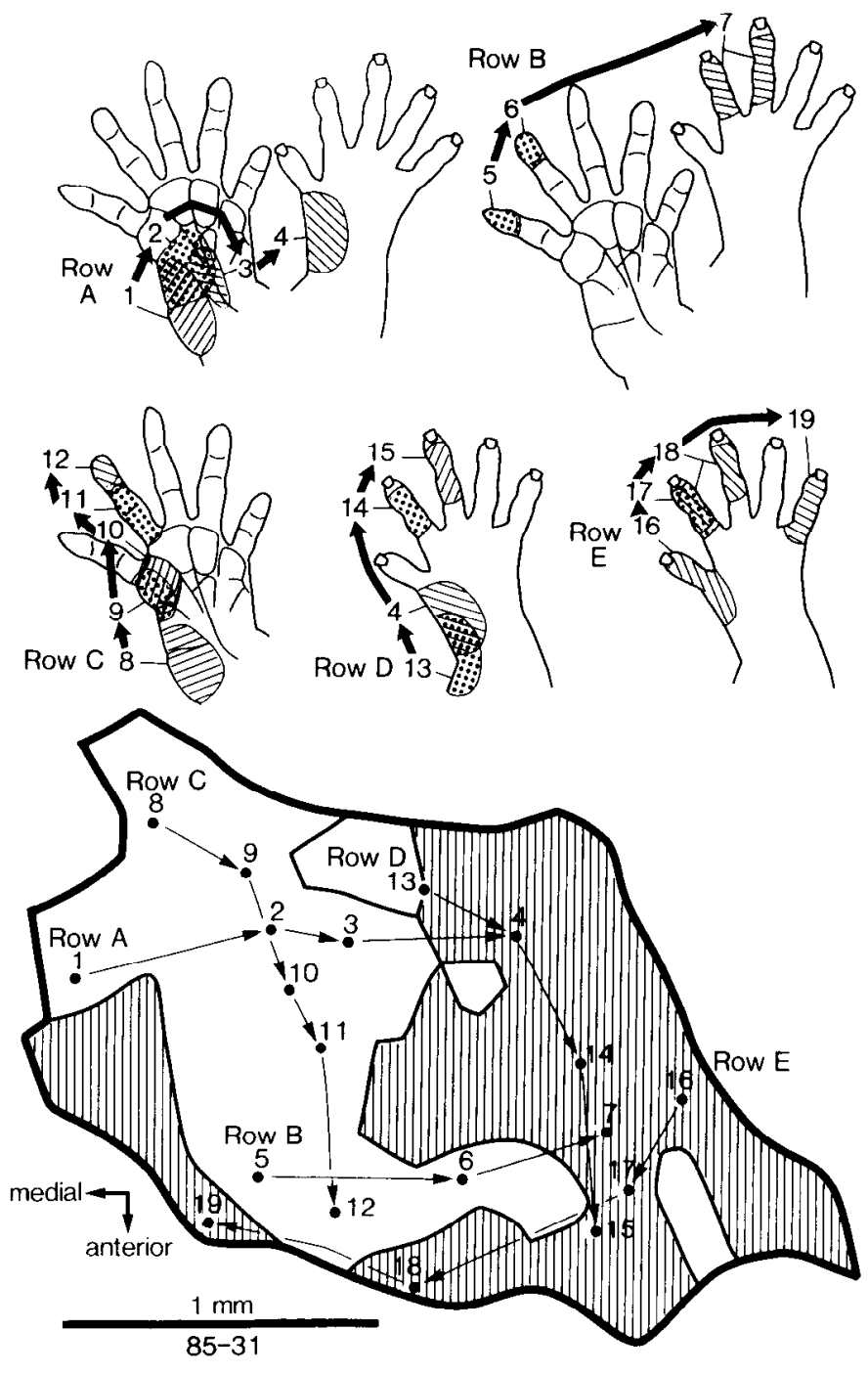

Figure 7. Map of the hand in a monkey reared after median nerve injury showing shifts in receptive fields (top) with mediolateral and caudorostral movements of recording sites (bottom). As in normal monkeys (e.g., Fig. 5), the caudorostral axis of the map corresponds to the proximodistal axis of the hand, the mediolateral cortical axis corresponds to the orthogonal axis across the hand, and the hairy (hatched) and glabrous (white) representations are in rough register. In contrast to normal monkeys, loss of the radial glabrous representation results in an abnormal adjacency of radial hairy and midhand glabrous receptive fields. Scale bar, $1 \mathrm{~mm}$.

topic reorganization following early peripheral injury (for reviews, see Kaas et al., 1983; Wall, 1988). The novel finding in the present study is that there is a strong correspondence between the features that, on the one hand, vary most in individual normal monkeys, and the features that, on the other hand, change most after median nerve injury. In both circumstances, the most variable features were properties of spatial patterning across somatotopically related aggregates of neurons. This correspondence suggests that the spatial integration features in monkeys reared with two nerves were produced by perturbations of the normal mechanisms for postnatal development and maintenance of these features.

Although it is presently difficult to identify specific mechanisms that were perturbed, it is possible to define a range of possibilities. From studies of human and nonhuman primates, 


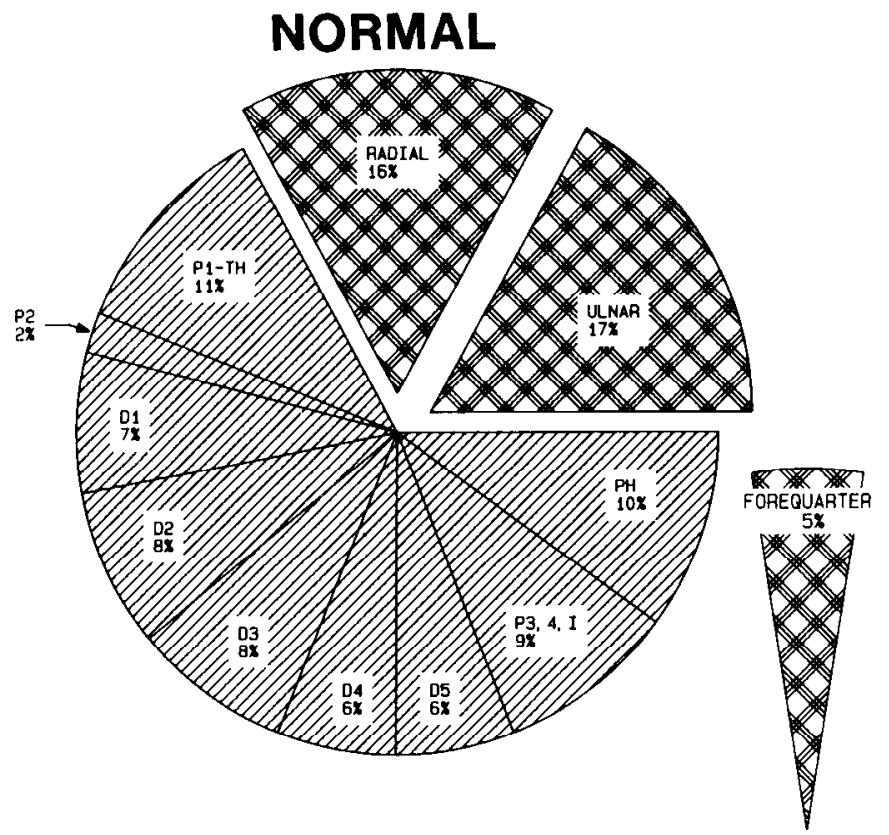

GLABROUS

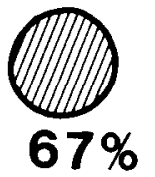

NORMAL MEDIAN
SECTION

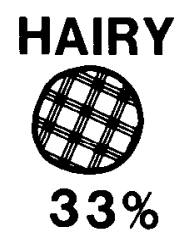

$47 \%$

$44 \%$
MEDIAN SECTION

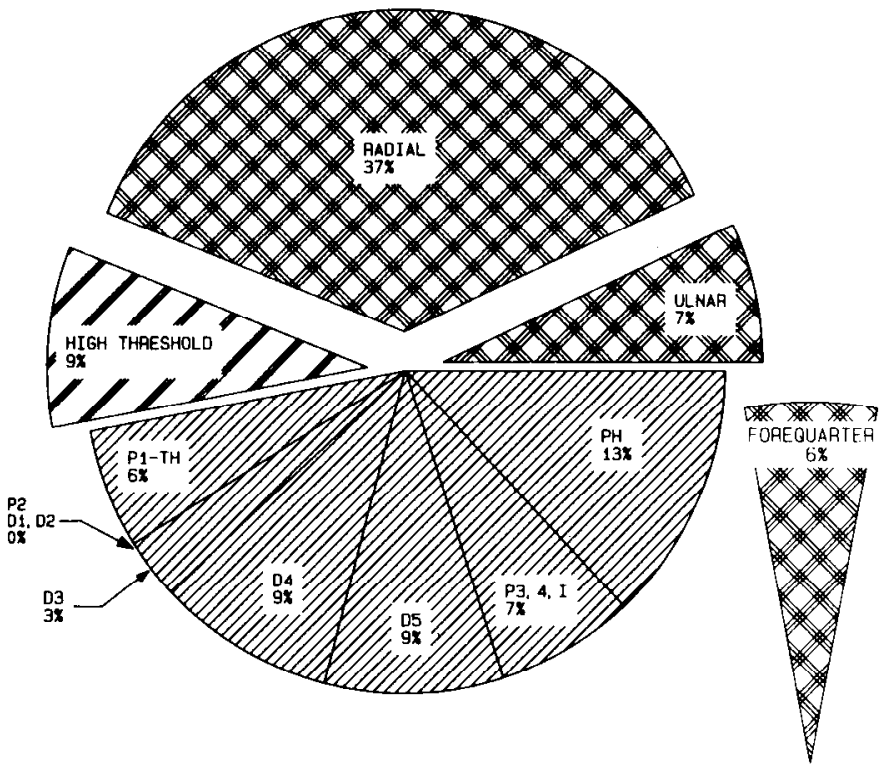

HIGH THRESHOLD<smiles></smiles>

$9 \%$

Figure 8. Mean percentage areas of the cortical hand map activated by different parts of the hand in normal monkeys and monkeys reared after median nerve section. The hatching patterns identified with glabrous, hairy, and high-threshold inputs (bottom) also apply to pie charts. In comparison to normal monkeys, monkeys with sectioned median nerves had (1) a smaller glabrous representation, (2) a larger hairy representation, (3) an area associated with high-threshold inputs, and (4) changes in the areas activated by radial and ulnar hairy inputs.

it is clear that the primate somatosensory system undergoes significant maturation prenatally and that, by birth, the ascending pathways are already formed and functional to some degree (e.g., Rakic, 1985; Rakic et al., 1986; Huntley et al., 1988; Krubitzer and Kaas, 1988; Peters and Jones, 1988; DarianSmith et al., 1990). It is also clear that a wide range of changes occur postnatally including, for example, changes in functional responsiveness (e.g., Gamstorp and Shelburne, 1965; Sitzoglou and Fotiou, 1985; Thatcher et al., 1987), synaptic density (e.g., Rakic et al., 1986; Johnston, 1988), thalamocortical fiber distribution (e.g., Darian-Smith et al., 1990), and expression of neurotransmitters and neuromodulators putatively related to neurite growth (e.g., Goldman-Rakic and Brown, 1982; Hendry et al., 1987; Huntley et al., 1988). Thus, these or related central mechanisms were potentially influenced by early median nerve injury. Peripheral factors also appear to have contributed to the observed cortical changes. Specifically, the finding that the postinjury features were clearly outside the range of normal variability suggests that central reorganization was guided in specific ways according to the available peripheral inputs. Currently, there is little understanding of how the periphery contributes to development of cortical maps in primates. In adult primates, the sizes of cortical representations are usually presumed to reflect differences in peripheral innervation density (e.g., Mount- castle, 1984). Although the present findings do not refute this view, it is difficult to explain certain changes parsimoniously in terms of innervation density. For example, following median injury the overlap skin representation increased in size despite some loss of innervation. In addition, despite no indications of denervation, the representations of the radial and ulnar hairy skin, respectively increased and decreased in size. Thus, it appears that peripheral factors are pertinent to postnatal cortical development but that innervation density is not the only factor of importance.

Conclusion 2. The representations of parts of the hand can develop and survive somewhat independently of each other

Postnatal section and ligation of the median nerve led to denervation of the radial glabrous hand and loss of the cortical representation of this skin. Despite this loss, highly organized representations were developed for other parts of the hand that remained innervated. These results suggest that the hand map is formed from a collection of representations that are capable of developing postnatally in a parcellated or disjunct fashion somewhat independently of each other.

Previous observations from studies of somatosensory pattern development are consistent with this conclusion. For example, the SI cortex of rodents contains functional representations of 


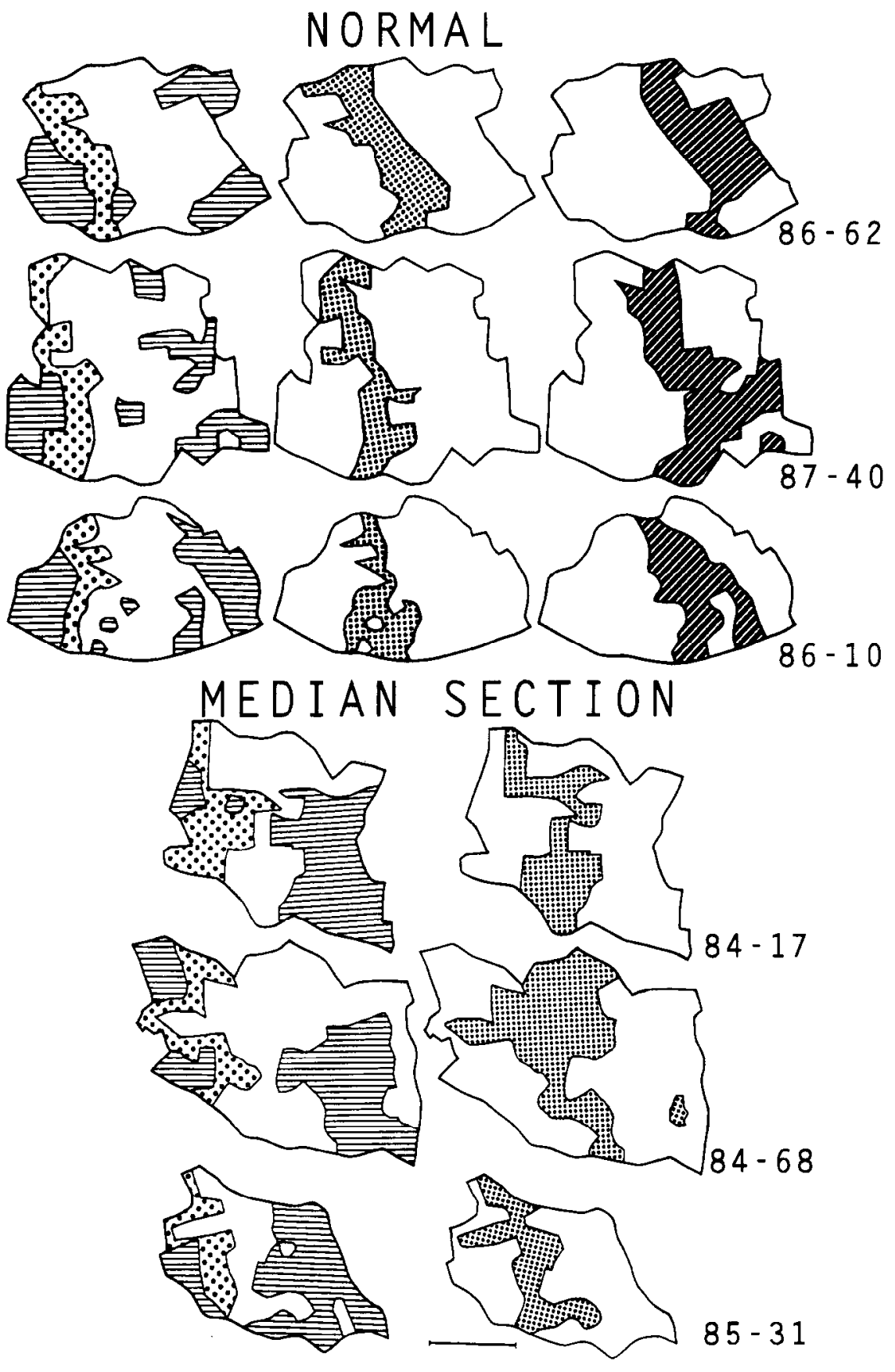

Figure 9. Hand maps showing changes in aggregation patterns of neurons that are activated by low-threshold inputs from skin territories of the hand nerves (and see Wall et al., 1992). Maps from three normal monkeys (i.e., $86-62,87$ 40 , and $86-10$ ) and three monkeys reared after median nerve section (i.e., 84-17,84-68, and 85-31) are indicated. Hatching in left-column maps indicates medial and lateral patchlike aggregates associated with hairy skin innervated, respectively, by the ulnar and radial nerves. Stippling in left-column maps indicates aggregate for glabrous skin innervated autonomously by the ulnar nerve. Stippling in middle-column maps of normal monkeys and right-column maps of median section monkeys indicates aggregate for glabrous skin with overlapping innervation from the median and ulnar nerves. Hatching in rightcolumn maps of normal monkeys indicates aggregate for glabrous skin in nervated autonomously by the median nerve. Following median nerve section loss of the autonomous median aggregate is correlated with fusion and enlargement of normal radial nerve aggregates in the lateral map and widening of the median and ulnar overlap aggregate in the central map. Medial, left; anterior, down. Scale bar, $1 \mathrm{~mm}$. vibrissae that are colocalized with organized aggregates of cells and thalamocortical terminations (e.g., Nussbaumer and Van der Loos, 1985; Simons et al., 1989; Killackey et al., 1990; Woolsey, 1990). Each of these aggregates is "place" specialized in that the dominant inputs originate from a "principal" vibrissa (e.g., Chapin, 1986; Armstrong-James and Fox, 1987; Simons et al., 1989). Peripheral injury in neonatal rodents leads to loss of normal functional representations in parts of the map associated with injured vibrissae; however, discrete functional representations still develop for vibrissae with intact innervation (e.g., Jeanmonod et al., 1981; Simons et al., 1984; Killackey et al., 1990; Woolsey, 1990). Thus, findings from both primates and rodents are consistent with the view that there are functional cortical aggregates that are capable of developing and surviving as somewhat independent "units" of a larger map.
If the cortical map of primates is developed in a parcellated fashion, one might expect to see reflections of this organization in the adult brain. Recent findings provide evidence for such adult parcellation. Briefly, rodlike aggregations of afferent terminations relating to a somatotopic part of the hand or face have been described in the spinal cord (Brown et al., 1989; Florence et al., 1989), brainstem (Culberson and Brushart, 1989; Florence et al., 1989; Noriega and Wall, 1991), and ventroposterior nucleus of the thalamus (Jones et al., 1982; Rausell and Jones, 1991) of adult monkeys. The thalamic aggregates, in turn, interface with area $3 \mathrm{~b}$ cortex via bundles of axons that terminate in patch- or striplike domains (e.g., Jones et al., 1982). These findings suggest that "place" information is processed by parcellated groupings of neuronal elements at different levels of the ascending neuraxis (e.g., see Jones et al., 1982; Wall et al., 1990; 
Noriega and Wall, 1991; Goyal et al., 1992). The present findings further suggest that each set of vertically connected aggregates that link a skin zone on the hand to an aggregate of cells in the cortex is capable of developing somewhat independently as a neuraxis "unit."

\section{Conclusion 3. The representations of parts of the hand interact to form maps of larger fractions of the hand surface}

Following postnatal section of the median nerve, a bandlike aggregate of cortical neurons in the lateral hand map was deprived of inputs. Inputs from parts of the hand served by intact nerves repartitioned this deprived band with no loss in the overall area of the hand map. These results suggest that inputs from a part of the hand are capable not only of independently establishing a cortical representation, but also of "competing" with inputs from other parts of the hand for a larger cortical space.

"Competition," as suggested by selective enlargement of particular representations, does not, however, appcar to be the only possible interaction. For example, following median section the increase in the representation of the radial hairy hand was offset by a decrease in the ulnar hairy representation. These size adjustments were further associated with a decrease in the overall number of patchlike hairy representations. The opposing nature of these size changes, and the coalescence of cortical patches suggest additional interactions also contributed to the changes in hairy representation.

\section{A working hypothesis}

The following hypothesis is suggested to summarize the present results. The area $3 \mathrm{~b}$ hand map normally consists of a collection of representations of all parts of the hand. These representations can develop and subsequently survive somewhat autonomously of each other. Following early median nerve injury, an incomplete map of the hand surface is formed from available ulnar and radial nerve inputs. Under such abnormal conditions, cortical features of spatial patterning change because peripheral factors impact on central mechanisms of somatotopic aggregation when developing parts of the map are interacting in "competitive" or other ways.

\section{References}

Armstrong-James M, Fox K (1987) Spatiotemporal convergence and divergence in the rat S1 "barrel" cortex. J Comp Neurol 263:265281.

Brown PB, Brushart TM, Ritz LA (1989) Somatotopy of digital nerve projections to the dorsal horn in the monkey. Somatosens Mot Res 6:309-317.

Chapin JK (1986) Laminar differences in sizes, shapes, and response profiles of cutaneous receptive fields in the rat SI cortex. Exp Brain Res 62:549-559.

Culberson JL, Brushart TM (1989) Somatotopy of digital nerve projections to the cuneate nucleus in the monkey. Somatosens Mot Res 6:319-330.

Darian-Smith C, Darian-Smith I, Cheema SS (1990) Thalamic projections to sensorimotor cortex in the newborn macaque. J Comp Neurol 299:47-63.

Florence SL, Wall JT, Kaas JH (1989) Somatotopic organization of inputs from the hand to the spinal grey and cuneate nucleus of monkeys with observations on the cuneate nucleus of humans. J Comp Neurol 286:48-70.

Frykman GK (1976) Peripheral nerve injuries in children. Orthop Clin North Am 7:701-716.

Gamstorp I, Shelburne SA (1965) Peripheral sensory conduction in ulnar and median nerves of normal infants, children, and adolescents. Acta Paediatr Scand 54:309-313.

Goldman-Rakic PS, Brown RM (1982) Postnatal development of monoamine content and synthesis in the cerebral cortex of rhesus monkeys. Dev Brain Res 4:339-349.

Goyal R, Rasey SK, Wall JT (1992) Current hypotheses of structural pattern formation in the somatosensory system and their potential relevance to humans. Brain Res, in press.

Hendry SHC, Jones EG, Killackey HP, Chalupa LM (1987) Choline acetyltransferase-immunoreactive neurons in fetal monkey cerebral cortex. Dev Brain Res 37:313-317.

Huntley GW, Hendry SHC, Killackey HP, Chalupa LM, Jones EG (1988) Temporal sequence of neurotransmitter expression by developing neurons of fetal monkey visual cortex. Dev Brain Res 43: 69-96.

Jeanmonod D, Rice FL, Van der Loos H (1981) Mouse somatosensory cortex: alterations in the barrelfield following receptor injury at different early postnatal ages. Neuroscience 6:1503-1535.

Johnston MV (1988) Biochemistry of neurotransmitters in cortical development. In: Cerebral cortex, Vol 7 (Peters A, Jones EG, eds), pp 211-236. New York: Plenum.

Jones EG, Friedman DP, Hendry SHC (1982) Thalamic basis of placeand modality-specific columns in monkey somatosensory cortex: a correlative anatomical and physiological study. J Neurophysiol 48 : 545-568.

Kaas JH, Merzenich MM, Killackey HP (1983) The reorganization of somatosensory cortex following peripheral nerve damage in adult and developing mammals. Annu Rev Neurosci 6:325-356.

Kalaska J, Pomeranz B (1979) Chronic paw denervation causes an age-dependent appearance of novel responses from forearm in "paw cortex" of kittens and adult cats. J Neurophysiol 42:618-633.

Kelahan AM, Ray RH, Carson LV, Massey CE, Doetsch GS (1981) Functional reorganization of adult raccoon somatosensory cerebral cortex following neonatal digit amputation. Brain Res 223:151-159.

Killackey HP, Ivy GO, Cunningham TJ (1978) Anomalous organization of SMI somatotopic map consequent to vibrissae removal in the newborn rat. Brain Res 155:136-140.

Killackey HP, Jacquin MF, Rhoades RW (1990) Development of somatosensory structures. In: Development of sensory systems in mammals (Coleman JR, ed), pp 403-429. New York: Wiley.

Krubitzer LA, Kaas JH (1988) Responsiveness and somatotopic organization of anterior pareital field $3 \mathrm{~b}$ and adjoining cortex in newborn and infant monkcys. Somatosens Res 6:179-205.

Mailander P, Berger A, Schaller E, Ruhe K (1989) Results of primary nerve repair in the upper extremity. Microsurgery 10:147-150.

Meisami E, Timiras PS (1982) Normal and abnormal biochemical development of the brain after birth. In: Biochemical development of the fetus and neonate (Jones CT, ed), pp 759-821. New York: Elsevier.

Mountcastle VB (1984) Central nervous mechanisms in mechanoreceptive sensibility. In: Handbook of physiology, Sec 1, The nervous system (Darian-Smith I, ed), Vol 3, pp 789-878. Bethesda, MD: American Physiological Society.

Noriega AL, Wall JT (1991) Parcellated organization in the trigeminal and dorsal column nuclei of primates. Brain Res 565:188-194.

Nussbaumer JC, Van der Loos H (1985) An electrophysiological and anatomical study of projections to the mouse cortical barrelfield and its surroundings. J Neurophysiol 53:686-698.

Peters A, Jones EG (1988) Cerebral cortex, Vol 7, Development and maturation of cerebral cortex. New York: Plenum.

Rakic P (1985) Limits of neurogenesis in primates. Science 227:1054 1056.

Rakic P, Bourgeois JP, Eckenhoff MF, Zecevic N, Goldman-Rakic PS (1986) Concurrent overproduction of synapses in diverse regions of the primate cerebral cortex. Science 232:232-235.

Rausell E, Jones EG (1991) Chemically distinct compartments of the thalamic VPM nucleus in monkeys relay principal and spinal trigeminal pathways to different layers of the somatosensory cortex. $J$ Neurosci $11: 226-237$.

Reisman JE (1987) Touch, motion, and propioception. In: Handbook of infant perception, Vol 1 (Salapatek P, Cohen L, eds), pp 265-303. New York: Academic.

Simons DJ, Durham D, Woolsey TA (1984) Functional organization of mouse and rat SmI barrel cortex following vibrissal damage on different postnatal days. Somatosens Res 1:207-245. 
Simons DJ, Carvell GE, Land PW (1989) The vibrissa/barrel cortex as a model of sensory information processing. In: Sensory processing in the mammalian brain (Lund JS, ed), pp 67-83. New York: Oxford.

Sitzoglou C, Fotiou F (1985) A study of the maturation of the somatosensory pathway by evoked potentials. Neuropediatrics 16:205208.

Thatcher RW, Walker RA, Giudice S (1987) Human cerebral hemispheres develop at different rates and ages. Science 236:1110-1113.

Wall JT (1988) Variable organization in cortical maps of the skin as an indication of the lifelong adaptive capacities of circuits in the mammalian brain. Trends Neurosci 1 1:549-557.

Wall JT (1990) Nerve dominance columns in the primate primary somatosensory (area 3b) cortex. Soc Neurosci Abstr 16:228.

Wall JT, Cusick CG (1986) The representation of peripheral nerve inputs in the S-I hindpaw cortex of rats raised with incompletely innervated hindpaws. J Neurosci 6:1129-1147.

Wall JT, Kaas JH, Sur M, Nelson RJ, Felleman DJ, Merzenich MM (1986) Functional reorganization in somatosensory cortical areas $3 b$ and 1 of adult monkeys after median nerve repair: possible relationships to sensory recovery in humans. J Neurosci 6:218-233.

Wall JT, Florence SL, Huerta MF, Kaas JH (1990) Functional and morphological aggregation in the somatosensory system of primates and its relevance for central reorganization after peripheral injury. In: Recent achievements in restorative neurology, Vol 3, Altered serlsation and pain (Dimitrijevic MR, Wall PD, Lindblom U, eds), pp 165-180. New York: Karger.

Wall JT, Huerta MF, Kaas JH (1992) Changes in the cortical map of the hand following postnatal ulnar and radial nerve injury in monkeys: organization and modification of nerve dominance aggregates. J Neurosci 12:3456-3465.

Weinstein S (1969) Neuropsychological studies of the phantom. In: Contributions to clinical neuropsychology (Benton AL, ed), pp 73106. Chicago: Aldine.

Woolsey TA (1990) Peripheral alteration and somatosensory development. In: Development of sensory systems in mammals (Coleman JR, ed), pp 461-516. New York: Wiley. 